\title{
Antimicrobial Combination Testing Method
}

National Cancer Institute

\section{Source}

National Cancer Institute. Antimicrobial Combination Testing Method. NCI Thesaurus.

Code C85558.

A method to determine the microbial susceptibility to two or more antibiotics. Numerical result translated into indifference, antagonism, synergism, or additive. 